\title{
Endoscopic Internal Urethrotomy (EIU) for the Treatment of Ureteral Stenosis: A Review of 233 Cases
}

\author{
Avion Kouassi Patrice ${ }^{*}$, Akassimadou N'Diamoi'1, Ouattara Fatoumata ${ }^{2}$, Aguia Brice1, \\ Zouan Fredy', Alloka Venance', Camara Sadia1, Bony Gnissan', Kramo Nykan³, \\ Anzoua Kacou${ }^{4}$, Dje Koffi ${ }^{1}$ \\ ${ }^{1}$ Department of Urology, University Hospital Center of Bouake, Bouake, Ivory Coast \\ ${ }^{2}$ Laboratory of Anatomy, Department of Urology, University Hospital Center of Treichville, Abidjan, Ivory Coast \\ ${ }^{3}$ Department of Urology, University Hospital Center of Cocody, Abidjan, Ivory Coast \\ ${ }^{4}$ Department of general surgery, University Center of Bouake, Bouake, Ivory Coast \\ Email: *avionkouassi@yahoo.fr, ndiamoi74@yahoo.fr, hadja_ouat@yahoo.fr,donbricofr@gmail.com, \\ docteurzouan@gmail.com, venancedagotchaka@gmail.com, docteur.ben.sadia.93@gmail.com, ubony07@gmail.com, \\ felicite.moke@gmail.com, ankib7@yahoo.fr,djekoff1958@gmail.com
}

How to cite this paper: Patrice, A.K., N'Diamoi, A., Fatoumata, O., Brice, A., Fredy, Z., Venance, A., Sadia, C., Gnissan, B., Nykan, K., Kacou, A. and Koffi, D. (2021) Endoscopic Internal Urethrotomy (EIU) for the Treatment of Ureteral Stenosis: A Review of 233 Cases. Open Journal of Urology, 11, 264-272.

https://doi.org/10.4236/oju.2021.117024

Received: April 29, 2021

Accepted: July 19, 2021

Published: July 22, 2021

Copyright $\odot 2021$ by author(s) and Scientific Research Publishing Inc. This work is licensed under the Creative Commons Attribution International License (CC BY 4.0).

http://creativecommons.org/licenses/by/4.0/ cC) (i) Open Access

\begin{abstract}
Background: Urethral stricture is a not uncommon pathology consisting of the narrowing of the urethra lumen with consequent reduction or cessation of urine flow. Objective: The objective is to retrospectively evaluate the results of treatment of urethral strictures by endoscopic internal urethrotomy in a series of 233 cases. Patients and Methods: It is Retrospective and descriptive study of 233 cases of urethral strictures treated by endoscopic internal urethrotomy under visual control in a private facility in Abidjan (Ivory Coast) over the period from 1 December 2007 to 31 December 2017. The study parameters were epidemiological, etiological, characteristics of the narrowing and the outcome of the treatment according to the predictive elements. Results: 233 patients were treated with endoscopic internal urethrotomy (EIU). All patients were male. The mean age of the patients was 49 years with extremes from 17 to 84 years. Dysuria (55.79\%) was the most frequent reason for consultation: the etiologies were infectious (51.50\%), traumatic (32.18\%), and iatrogenic (13.73\%) and not found (2.57\%). Retrograde urethrocystography with fictional films performed in all patients showed the following characteristics: the stricture was bulbar (81.04\%), unique (55.79\%) and short in 68.6\%. There was a $39.91 \%$ good outcome after the first EUS. The average follow-up was 3 years. Mortality was nil and morbidity was assessed at $4.72 \%$. The result was better when the procedure concerned a short $(\leq 3 \mathrm{~cm})$, single stenosis on the posterior urethra. The average duration of the postoperative urinary catheter
\end{abstract}


was 14 days on average. The poor results (60.08\%) were observed in cases of long stenosis, located on the anterior urethra or concerning elderly patients. 69.28\% were cured after a second urethrotomy; the remaining cases were managed by urethroplasty or urethral dilatation. Conclusion: IEU is a simple, reproducible and attractive procedure with an overall success rate of $81.54 \%$ in 3 years. Its indication must be made in the case of short stenosis, single posterior and in the young subject.

\section{Keywords}

Stenosis, Urethra, Endoscopic Internal Urethrotomy

\section{Introduction}

Urethral stricture or urethral stenosis is a narrowing of the urethral lumen usually resulting from ischaemic spongiofibrosis. In Africa, in general, and in Ivory Coast in particular, it represents a late complication of sexually transmitted infections and trauma [1]. Its diagnosis is evoked in front of urinary disorders of the lower apparatus, infectious or traumatic antecedents and confirmed by retrograde urethrocystography with fictional pictures. Management is difficult and a real challenge in Urology. The various techniques of open repair are known to urologists as well as the related postoperative problems which are related to the importance of the lesions often extended and to the sepsis in connection with our working conditions with its procession of complications [1]. The endoscopic internal urethrotomy is a simple method, of fast realization, devoid of major morbidity and requiring only a short hospitalization. The aim of our work is the retrospective evaluation of the results of the treatment of urethral strictures by endoscopic internal urethrotomy in a series of 233 cases.

\section{Patients and Methods}

This is a retrospective and descriptive study conducted from December 1, 2007 to December 31, 2017 in a private facility in Abidjan (Ivory Coast); 233 male patients were treated by endoscopic internal urethrotomy. The diagnosis of urethral stricture was made on the basis of a history of sexually transmitted infection, trauma to the pelvis or urethra after bladder catheterization, clinical evidence and diagnostic confirmation by retrograde urethrocystography with voiding films showing the location, number and length of the stricture as well as its impact on the upstream pocket. All urethrotomy was performed after a standard prior operative workup and after ensuring the sterility of the urine from the urine cytobacteriological examination. All urethrotomy was performed using a cold blade urethrotomy (STORZ) with $0^{\circ}$ optics. The procedure was performed under loco-regional anaesthesia. Sectioning of the stricture was performed under visual control at 12 o'clock from front to back until the peri-urethral tissue was visible. It extended in the digital plane to the healthy mucosa. The irrigation flu- 
id used was saline (9\% saline). A CH20 urethral catheter was used to drain the urine postoperatively for 14 days. After removal of the catheter, the postoperative follow-up was 3 years for each patient. It includes:

- Clinical: fictional comfort;

- Radiological: retrograde urethrocystography;

The parameters studied were epidemiological, etiological and the result of the treatment according to predictive criteria.

Outcome evaluation criteria:

- Good outcome;

- Patient has comfortable voiding;

- Patient has no voiding problems;

- Normal retrograde urethrocystography;

- No post-void residual.

Poor result (two criteria present):

- Patient has uncomfortable voiding;

- Presence of voiding disturbance;

- retrograde urethrocystography: urethral stricture;

- Presence of post-void residual.

The predictive criteria for the outcome of the urethrotomy were:

- Age;

- Characteristics of the stricture (location, length, number).

The data were collected from the patients' files, a survey form and the register of surgical reports of patients operated on for urethral stricture. All data were entered into the WORLD software and processed with Epi info 2.10.

We have protected the confidentiality of the information collected during the survey. Thus, an anonymity number was assigned to each survey form with prior authorization obtained from the administrative and health authorities.

\section{Results}

\subsection{Clinical Data}

1) Circumstances of discovery

Dysuria is the most frequent circumstance of discovery with $55.79 \%$ (Table 1, $\mathrm{n}=130)$.

2) Etiology

Infectious causes are frequent with $51.50 \%(n=120$, Table 2).

\subsection{Radiographic Data Retrograde Urethrocystography}

1) Site

The bulbar urethra is the predominant site with $81.54 \%(\mathrm{n}=190$, Table 3$)$.

2) Number of narrowings

Single narrowing represents $56 \%(n=125$, Table 4$)$.

3) Extent of narrowing

Short narrowing represents $68.6 \%(\mathrm{n}=160$, Table 5). 
Table 1. Distribution of patients according to discovery circumstance.

\begin{tabular}{ccc}
\hline Circumstance of discovery & Number & Percentage \\
\hline Dysuria & 130 & 55.79 \\
Acute or chronic retention of urine & 70 & 30.04 \\
Urinary urgency associated with & 13 & 5.57 \\
urinary frequency or burning & 12 & 5.15 \\
Recurrent epididymitis & 8 & 3.43 \\
Urethral fistula & 233 & 100 \\
TOTAL & & \\
\hline
\end{tabular}

Table 2. Distribution of patients according to the aetiology of narrowing.

\begin{tabular}{ccc}
\hline Etiology & Number & Percentage \\
\hline Infectious & 120 & 51.50 \\
Traumatic & 75 & 32.18 \\
Iatrogenic & 32 & 13.73 \\
Not found & 06 & 2.57 \\
TOTAL & 233 & 100 \\
\hline
\end{tabular}

Table 3. Distribution of patients by site.

\begin{tabular}{ccc}
\hline Parameter & Numbers & Percentage \\
\hline Bulbar urethra & 190 & 81.54 \\
Penile & 33 & 14.16 \\
Bulbo-membranous & 10 & 4.29 \\
TOTAL & 223 & 100 \\
\hline
\end{tabular}

Table 4. Distribution according to the number of strictures.

\begin{tabular}{ccc}
\hline Number & Number & Percentage \\
\hline Single & 130 & 55.79 \\
Multiple & & \\
$\leq 3$ & 70 & 30.04 \\
$\geq 3$ & 33 & 14.16 \\
TOTAL & 233 & 100 \\
\hline
\end{tabular}

Table 5. Distribution of patients according to the extent of the stricture.

\begin{tabular}{ccc}
\hline Extent & Number & Percentage \\
\hline Short $\leq 3 \mathrm{~cm}$ & 160 & 68.6 \\
Long $>3 \mathrm{~cm}$ & 72 & 30.9 \\
Unspecified & 1 & 0.42 \\
TOTAL & 233 & 100 \\
\hline
\end{tabular}


The cytobacteriological examination of the urine showed a urinary infection in 92 patients (39.48\%); the most frequent germ was Escherichia coli in 72 patients $(78.26 \%)$. The patients were treated with antibiotics adapted to the preoperative antibiogram. The $\mathrm{CH} 20$ urethral catheter was left in place for an average of 14 days, with extremes of 3 to 21 days depending on the extent of the stenosis, in cases of difficult endoscopic internal urethrotomy and significant urethral fibrosis.

The average duration of the procedure was 15 minutes with extremes of 5 to 45 minutes.

The average hospital stay was 3 days with extremes of 1 to 6 days.

The operative morbidity was $4.72 \%(\mathrm{n}=11)$ represented by:

- Six (6) false routes benefited from a second endoscopic internal urethrotomy (EIU) with favorable outcome one week after the first urethrotomy. Two (2) scrotal fluid extravasations were resolved by suspension of the bursa. One urinary tract infection and one orchid epididymitis treated with antibiotic therapy adapted to the antibiogram. One patient presented with transient sexual impotence which resolved spontaneously with time. Infectious complications and false routes all occurred in patients with an extensive stricture.

- Operative mortality was zero.

\section{Overall Results}

- 93 patients (39.91\%) had a good outcome immediately after removal of the urinary catheter. This result remained the same throughout the study period. 140 patients $(60.08 \%)$ had a poor outcome after the first endoscopic internal urethrotomy with recurrence occurring on average 18 months with extremes from 1 to 36 months. Of these patients, 97 (69.28\%) were definitively treated after a second EIO. The remaining 43 patients were never cured by UIE even after a third urethrotomy attempt.

A TOTAL of 190 patients out of $233(81.54 \%)$ were cured after one $(n=93)$ or two $(n=97)$ endoscopic internal urethrotomy. The 43 patients not cured by EUS were treated by urethral dilation $(\mathrm{n}=32 ; 13.73 \%)$ or urethroplasty $(\mathrm{n}=11$; $4.72 \%)$.

- Two-year (36 months) outcomes by predictors.

We found 86.84 good results for posterior urethral strictures (165 patients) versus $13.15 \%$ for penile strictures (25 patients); for short strictures less than or equal to $3 \mathrm{~cm}$ (156 patients), the results were good in $82.1 \%$ versus $17.85 \%$ for long strictures greater than or equal to $3 \mathrm{~cm}$ (34 patients) Beyond three areas of narrowing, the rate of poor results was $100 \%$.

We found $79.4 \%$ good results $(n=151)$ in the group of patients under 45 years of age $(n=189)$ against $20.52 \%$ (39 patients) in the group of patients over 55 years of age $(n=44) .77 .33 \%(n=58)$ of good results were found for narrowing of traumatic origin, $56.2 \%(n=18)$ for iatrogenic causes and finally $45.83 \%$ for infectious causes. 


\section{Discussion}

Urethral stricture is a not uncommon pathology in urology and can occur at any age. In our study, the mean age of the patients was 49 years ( $17-84$ years); in a similar study in Cameroon, 49 patients were recorded and the mean age was 47.6 [2]; in Togo, the mean age of the patients was 44.4 years [3]; in North Africa (Morocco), 244 patients had a mean age of 51 years [4]. The results show that urethral stricture is pathology of the adolescent and young adult. Indeed, sexual freedom, extended to the plurality of partners on the one hand, and on the other hand, sexually transmitted diseases that affect mainly adolescents and young adults who constitute the sexually active population could explain these results. Our study recorded only men. Urethral stricture is a rare condition in females and the literature reports only one case in a series of 112 patients in Kenya [5].

Dysuria is the major finding of urethral stricture in our study with $55.79 \%$. This finding is similar to that of other authors on the African continent, Ngaroua in Cameroon 70.17\% [6], Hounnasso in Togo 48.1\% [3], and Benjelloun in Morocco $82 \%$ [4]. Dysuria is explained by the fact that urethral stricture is a reduction in the lumen of the urethra resulting in an obstacle to the flow of urine out of the bladder. They can be infectious, traumatic and iatrogenic [1] [2] [3] [4]. In our study, the main etiologies were infectious and traumatic. Indeed, we recorded $51.50 \%$ of infectious aetiologies. This predominance of infectious causes is also found in the studies of several African authors [1] [2] [3] [4]. This result could be explained by the low socio-economic level, poor hygiene conditions and risky behavior and the plurality of sexual partners favoring sexually transmitted infections. Traumatic aetiology came second to infectious causes with $32.18 \%$. The narrowing of the urethra as a result of trauma accounts for road accidents and late consultations. The iatrogenic causes are due in our practice to iterative catheterization and/or prolonged wearing of urinary catheters after adenomectomy complicated by vesico-cutaneous fistulas. However, in developed countries, iatrogenic causes are most often due to endoscopic maneuver [7] [8] [9]. In our study, analysis of the characteristics of urethral strictures revealed the following: the strictures were essentially bulbar (81.54\%), single (55.79\%) and short (68.6\%), as in the series by Benjelloun et al in Morocco [4], Hounnasso in Togo [3], Moby in Cameroon [2] and Ndour in Senegal [10]. On the other hand, Zongo et al in Burkina Faso reported a predominance of long and multiple strictures, respectively $69 \%$ and $75 \%$ [11]. In our series of 233 patients with urethral strictures with a 3-year follow-up, we report an overall cure rate of $81.54 \%$ of cases. Our results are comparable to those reported in the series of Ngaroua which is $87.73 \%$ of cure rate while Ahmed [12] reports only $58.1 \%$ of cure rate. The bulbar site could be explained by the configuration of the bulb whose cul-de-sac constitutes a reservoir where germs swarm due to urinary stasis. For Culty [13], endoscopic internal urethrotomy is more often unsuccessful in post-traumatic stenosis than in post-infectious stenosis [13]; for André, the results are less good in sclero-inflammatory stenosis [12], whereas for post-traumatic stenosis the re- 
sults are better [8]. For Ahmed, the best results are obtained when it is a stenosis of the proximal urethra [12]. In our series, we recorded $60.08 \%$ of recurrences. They appear late, on average 18 months after the first EUS. A second urethrotomy was proposed in these cases with $69.28 \%$ success rate, but a poor outcome after a second urethrotomy was never improved by an additional urethrotomy. The results of our study analyzed at 24 months, show that good results are obtained in young subjects with short, single and posterior strictures. In contrast, poor results were observed in patients with extensive and multiple strictures. In our series, the urethral tube was left in place for an average of 14 days, whereas Benjelloun in Morocco left the catheter in place for two days. The duration of 14 days in our series could be explained by the often difficult urethrotomy due to the important fibrosis of the stricture on the one hand and on the other hand the false routes in case of extensive stenosis. However, prolonged catheterization has not been shown to improve the outcome of urethrotomy [1] [4]. The morbidity of endoscopic internal urethrotomy is minimal and is known from the literature [14] [15] [16]. In our series, the morbidity was $4.72 \%$. The literature reports a morbidity rate of between $4 \%$ and $9.5 \%$ [1] [4] [9] [17]. This low morbidity found in our study confirms the thesis according to which endoscopic internal urethrotomy is devoid of major morbidity claimed by several authors with regard to open surgery [1] [4] [7] [8] [12].

\section{Conclusion}

Endoscopic internal urethrotomy is a simple procedure, easy to perform, repetitive and attractive in view of the overall success rate which is $81.54 \%$ at 3 years in our study. It should be offered as a first-line procedure to patients with any short, single and proximal stenosis in young subjects. Open surgery should be indicated in case of failure after two attempts of endoscopic internal urethrotomy. This study has limitations that must be taken into account when interpreting the results. As this is the retrospective nature with significant loss of information.

\section{Contributions of the authors}

AVION Kouassi Patrice, AKASSIMADOU N'diamoi, OUATTARA Fatoumata, AGUIA Brice, ZOUAN Fredy, ALLOKA Venance, CAMARA Sadia, BONY Gnissan: Performing statistical analysis and proofreading the article. KRAMO Nykan, ANZOUA Kacou, DJE Koffi: Documentary research and formatting of the work.

\section{Ethical Considerations}

We have protected the confidentiality of the information collected during the survey. Thus, an anonymity number was assigned to each survey form with prior authorization obtained from the administrative and health authorities.

\section{Conflicts of Interest}

The authors declare that they have no conflicts of interest. 


\section{References}

[1] Dje, K., Coulibaly, A., Coulibaly, N. and Sangaré. I.S. (1999) L'uretrotomie interne endoscopique dans le traitement du rétrécissement urétral acquis du noir Africain à propos de 140 cas. Médecine d' Afrique noire électronique, 46, 56-61.

[2] Moby, E.H., Makon, S., Eyongueta, D., Kamadjou, C., Sala, B.T., Happy, S., et al. (2018) Traitement des sténoses de l'urètre par uretrotomie interne endoscopique: profil épidémiologique, clinique et thérapeutique à Douala. Revue de médecine et de pharmacie, 8, 775-783.

[3] Hounnasso, P.P., TRaore, S.R., Avakoudjo, J.D.G., Yevi, I.D.M., Natchagande, G., agou-nkpe, M.M., et al. (2015) Aspects épidémiologiques et diagnostiques du rétrécissement de l'urètre masculin au Centre Hospitalier et Universitaire HUBERT Koutougou MAGA de Cotonou. Uro' Andro, 1, 162-165.

[4] Benjelloum, M., Drissi, M., Makhloufi, M., Nouri, A., Karmouni, T., Tazi, K., et al. (2008) Traitement des sténoses de l'urètre par l'uretrotomie interne endoscopique: Résultats anatomiques et fonctionnels d'une série de 244 cas. African Journal of Urology, 14, 114-119. https://doi.org/10.1007/s12301-008-0002-3

[5] Magulo, E.L., Bwombwongo, S.O. and Ayuo, P.O. (2013) A Etiology of Urethal Structures at Moi Teaching and Refferal Hospital. Annals of African Surgery, 10, 11-13

[6] Ngaroua, Ngah, J.E., Yaouba, D., Ousmane, A. and Amvene, J.M. (2017) Aspects épidémiologiques, cliniques et prise en charge de sténose urétrale chez l'adulte dans un hôpital de District de Ngaoundéré, Cameroun. Pan African Medical Journal, 26, 193-198. https://doi.org/10.11604/pamj.2017.26.193.9669

[7] Furr, J. and Gelman, J. (2020) Endoscopic Management of Urethral Structure Disease and Bladder Neck Contractures. Journal of Endourology, 34, 7-12.

https://doi.org/10.1089/end.2018.0317

[8] Cavalcanti, A.G. and Fiedler, G. (2015) Substitution Urethroplasty or Anastomotic Urethroplasty for Bulbar Urethar Structures? Or Endoscopic Urethrotomy? International Brazilian Journal of Urology, 41, 619-622. https://doi.org/10.1590/S1677-5538.IBJU.2015.04.03

[9] Isen, K. and Nalçacioglu. V. (2015) Direct Vision Internal Urethrotomy by Using Endoscopic Scissors. International Urology and Nephrology, 47, 905-908. https://doi.org/10.1007/s11255-015-0960-x

[10] Ndour, N.S., Diame, D.I., Diallo, Y., Kouka, S.C., Ndiaye, M., Diallo, I., et al. (2018) Prise en charge du rétrécissement de l'urètre. Uro' Andro, 1, 128-132.

[11] Zongo, B., Kambou, T. and sanou, A. (2003) Uretrotomie interne endoscopique pour rétrécissement urétral acquis à l'hôpital de Bobo-Dioulasso: faisabilité de la technique dans les conditions précaires et résultats à court terme. Bulletin de la Société de Pathologie Exotique, 96, 92-95.

[12] Ahmed, M.H., Ahmed, E.A., Osama, M., Amr, A., Elbakry, M.T., Helmy, O., et al. (2015) Is There a Way to Predict Failure after Direct Vision Internal Urethrotomy for Single and Short Bulbar Urethral Structures? Arab Journal of Urology, 13, 277-281. https://doi.org/10.1016/j.aju.2015.07.007

[13] Culty, T., Ravery, V. and Boccon-Gibod, L. (2007) Les Sténoses post-traumatiques de l'urètre: A propos de 105 cas. Progrès en Urologie, 17, 83-91. https://doi.org/10.1016/S1166-7087(07)92231-9

[14] Salifou, I.T., Ousmane, D., Amadou, M., Soumaila, T., Aly, B.D., Toure, L., et al. (2019) Prise en charge de la sténose urétrale acquise: notre expérience dans le service chirurgie général de SIKASSO. The Pan African Medical Journal, 33, 328-345. 
[15] Amr, E.D., Mohamed, M.G., Islam, F.A., Atef, M.A., Abdel-Moneim, M.A. and Hisham, M.H. (2019) Uretral Structure after Ureteroscopy for Stones: A Prospective Study for the Incidence and Resk Factors. Urology Annals, 11, 276-281.

https://doi.org/10.4103/UA.UA_110_18

[16] Nadir, I.O. and Christopher, R.C. (2020) Is Urethotomy as Good as Urethroplasty in Men with Recurrent bulbar Urethral structures? European Urology, 78, 581-582. https://doi.org/10.1016/j.eururo.2020.07.028

[17] Modou, N., Ndiaga, S.N., Oumar, G., EL Hadji, M.D., Ngor, M.T., Ousmane, S.O.W., et al. (2020) Internal Endoscopic Urethrotomy for Urethral Structures: Evaluation of Results and Influenzating Factors. International Journal of Advanced Research, 8, 1100-1104. https://doi.org/10.21474/IJAR01/12259 